\title{
Ossification of the posterior longitudinal ligament in the thoracic spine causing intermittent paraplegia in an Englishman: case report
}

\author{
H Nakamura MD PhD,${ }^{1} \mathrm{H}$ V Crock AO MD MS FRCS FRACS, ${ }^{2}$ B P Galbally MBBS \\ FRACP ${ }^{2} \mathrm{~J}$ Dawson MA MB Bchir FRCP FRCR ${ }^{2}$
}

\author{
${ }^{1}$ Osaka University City Hospital, Osaka, Japan, ${ }^{2}$ Cromwell Hospital, Cromwell Road, \\ London SW5 OTU, England.
}

Compression of the spinal cord due to ossification of the posterior longitudinal ligament (OPLL) often leads to quadriplegia or paraplegia in Japanese patients. This disease is uncommon in other races. We report the case of a middle-aged Englishman who presented with complaints of intermittent paraparesis due to OPLL at the T5-T6 level in his thoracic spine.

Key words: ossification of posterior longitudinal ligament; paraplegia; caucasian.

\section{Case history}

A 46 year old white Englishman entered hospital in February 1988 for removal of impacted teeth. One week later after discharge from hospital, while walking to a railway station, his legs suddenly 'turned to jelly' and he lost his balance for about 10 minutes.

Over the course of the next 6 months he developed widespread symptoms including spinal pain, increasing difficulty in walking, sensory disturbances in his trunk and legs and change of bowel habit. In particular he had noted feelings of numbness and tingling, coldness and heaviness in his legs, often worse on the right side and extending upwards to his trunk. He was aware of low back pain and sometimes of a tight sensation around his chest and waist on both sides.

At times he staggered after walking only a few hundred yards. He became fearful of using escalators because of loss of balance and giving way of his legs. Many of these symptoms were intermittent and even fleeting. When first examined by a physician in February 1988, apparently no abnormalities were detected. He consulted different doctors over the next few months and went to the London School of Osteopathy of his own accord.

In August 1988 he was referred to us. Examination at that time revealed ex-

Correspondence: Dr H V Crock. tremely brisk lower limb reflexes with bilateral ankle clonus and increased tone in both legs. The plantar responses were equivocal. Position sense in the toes was abnormal and vibration sense was absent at the ankles. His gait was unsteady. No clearly defined pattern of sensory impairment to pin prick was noted, apart from a vague sensory level at about $\mathrm{T} 7$ and numbness extending down the right leg. Examination of his upper limbs and cranial nerves revealed no abnormalities.

\section{Radiological findings}

Plain radiographs of the thoracic spine were not helpful in identifying the cause of the intermittent disturbances of spinal cord function in this patient. Computerized tomograms were obtained on 14.8.89 with images in the horizontal sagittal and coronal planes (Figs 1 and 2). These showed a massive intraspinal calcification at T5/6 compressing the thoracic cord.

\section{Surgical treatment}

The patient was advised to have surgery because he had continued to deteriorate between 14.8.89 when the CT scan was obtained and the date of his admission to hospital on 2.9.89.

He was told that without operation further deterioration appeared inevitable 


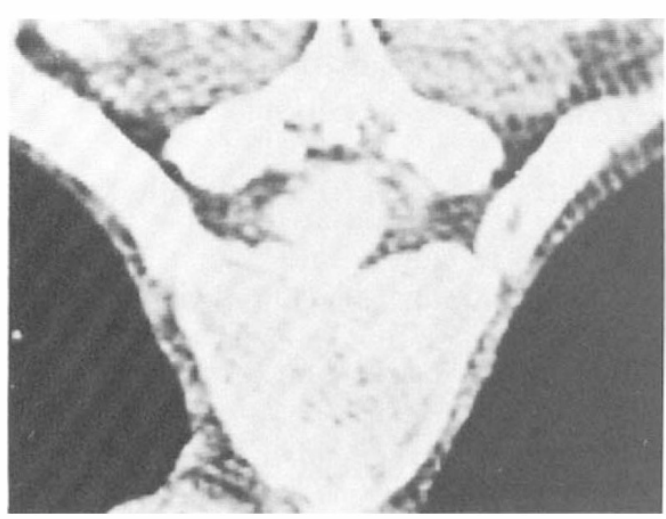

Figure 1 14.8.89: Preoperative CT, $2 \mathrm{~mm}$ thick slice axial scan, straight gantry, shows a lobulated calcified mass arising from the lower posterior surface of T5. Posteriorly, there is some calcification of the ligamentum flavum.

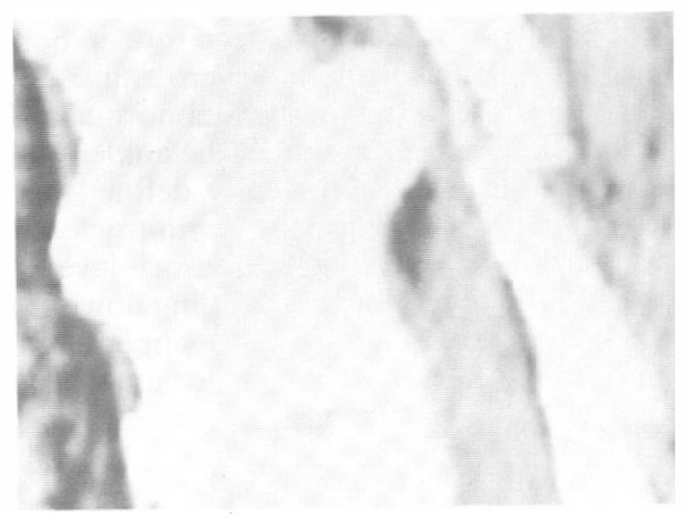

Figure 2 14.8.89: Preoperative CT, sagittal reformatted image mid line shows the calcified mass partially bridging the $\mathrm{T} 5 / 6$ disc space posteriorly and virtually occluding the spinal canal. There are spondylitic changes anteriorly and calcification in the ligamentum flavum.

and that it would lead to paraplegia. The potential danger of irreversible cord injury resulting from surgery was discussed with him in conference with members of the team. It was suggested that the lesion was perhaps a calcific mass related to the intervertebral disc, though it was considered more likely to be a benign osteochondroma arising from $\mathrm{T} 5$ vertebral body.

\section{Operation}

The patient was placed in the lateral position lying on his right side with his left arm elevated forwards and cranially, resting on a gutter support. His chest was opened through the bed of the left fourth rib, the middle two-thirds of which was excised. This segment of rib was duly cut into 3 discs for use later as vertebral interbody grafts using a gauge 2 dowel cutter.

A vertical incision was made in the parietal pleura along the mid lateral line of the vertebral bodies of T4, T5 and T6. The intervertebral disc between $\mathrm{T} 5$ and $\mathrm{T} 6$ was exposed with blunt dissection, without division of the regional intercostal vessels. The sympathetic plexus was also left undisturbed. Identification of vertebral levels is always difficult during operations on the upper thoracic spine when performed via thoracotomy. In this case the upper ribs were counted by palpation within the pleural cavity to lead to the intervertebral disc between T5 and T6.

The thoracic aorta was retracted to the mid line leaving the left lateral side of the intervertebral disc clearly defined. A gauge 1 dowel cutting instrument was used to prepare a cavity passing transversely across the spine to a depth of about $2.7 \mathrm{~cm}$. The cutter produced a circular defect occupied by ellipses of the vertebral bodies of $\mathrm{T} 5$ and T6 with the intervertebral disc remaining intact between the opposing vertebral endplates. These tissues were then removed as a single plug.

The intervertebral disc was friable and yellowish in colour, but with no sign of calcification. Using a long handled fine curette and fine straight pituitary rongeurs, the bulk of remaining disc tissue and the vertebral endplate cartilages were removed. The head and neck of the left fifth rib were excised to expose the margin of the intervertebral disc related to the anterior wall of the thoracic spinal canal. The inferior postero lateral margin of the vertebral body of T5 was curetted away together with disc remnants using a long handled fine curved curette. Gradually the mass demonstrated on CT came into view. It was a circumscribed bony mass resembling faded ivory with the consistency of cortical bone. It was firmly adherent to the dural sac behind it.

The posterior walls of the dowel cavity were breached carefully using curettes so 
that all force was directed away from the spinal canal. The outlines of this ossified tissue were defined with fine curettes and eventually it prolapsed forward into the dowel cavity, carrying the dural sac with it. It was unfortunate that it was not possible to use a high speed diamond tipped drill here, so deep in the thorax, when it has been of so much value in the surgery of spinal canal stenosis, especially cervical.

Following the decompression of the anterior aspect of the thoracic spinal canal the dural sac expanded. The bony plaque remained attached to its anterior wall but when pressed on gently with a probe it would ballot, indicating that CSF was now flowing around the spinal cord.

The rib grafts previously prepared as discs were impacted one on top of the other into the dowel cavity (Fig 6).

The chest was closed in the usual manner with a single underwater seal drain, led out through the lower part of the thorax.

\section{Postoperative course}

Within 24 hours the patient reported improvement in the power of his legs and no sign of sensory impairment to pin prick could be detected on his trunk or legs.

$\mathrm{He}$ voided urine without difficulty but bowel sounds were absent and a serious paralytic ileus developed which persisted for 2 weeks. Nasogastric drainage with inter-

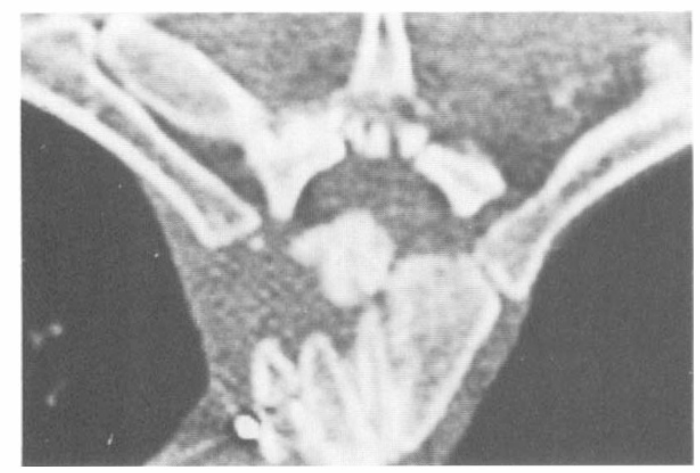

Figure 3 16.10.89: Postoperative CT $2 \mathrm{~mm}$ axial image shows partial resection of the vertebral body on the left with bony grafts anteriorly. The osteoma-like fragment has moved anteriorly out of the spinal canal. mittent suction and intravenous therapy to cover maintenance and replacement fluids, as well as parenteral nutrition were instituted. Abdominal distension was marked, leading to impaired ventilation and at times reduced cardiac output. His general condition was poor at this time.

On review 6 months after operation, gait and balance had returned to normal and he was pain free. Lower limb reflexes remained brisk but clonus had ceased and the plantar responses were normal. The radiological changes were followed using CT scanning and showed signs of progressive improvement (Figs 3, 4, 5 and 6).

\section{Discussion}

One of the earliest autopsy reports on a patient with ossification of the posterior longitudinal ligament (OPLL) was published by Tsukimoto ${ }^{1}$ in 1960 . He described the lesion which had been found extending over $\mathrm{C} 3$ and $\mathrm{C} 4$ vertebral bodies, flattening the spinal cord at those levels.

Throughout that decade, there appeared from Japan an increasing number of reports on this condition which became known in other parts of the world as 'The Japanese Disease.' Three cases of cervical OPLL, 2 in Anglo Saxons living in Australia and one in a Japanese sailor visiting Western Australia were reported by Breidahl ${ }^{2}$ in 1969 .

Recognising the prevalence of this disease, the Ministry of Public Health and Welfare of Japan set up a special study

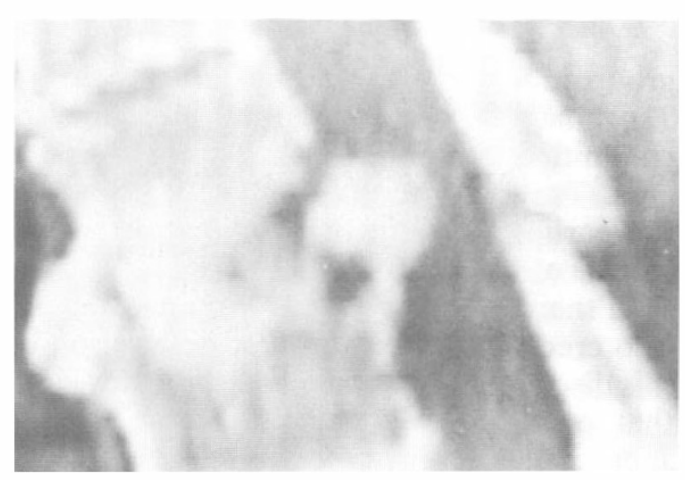

Figure 4 16.10.89: Postoperative CT, reconstructed sagittal image shows further retraction of the ossified mass into the operation bed. 


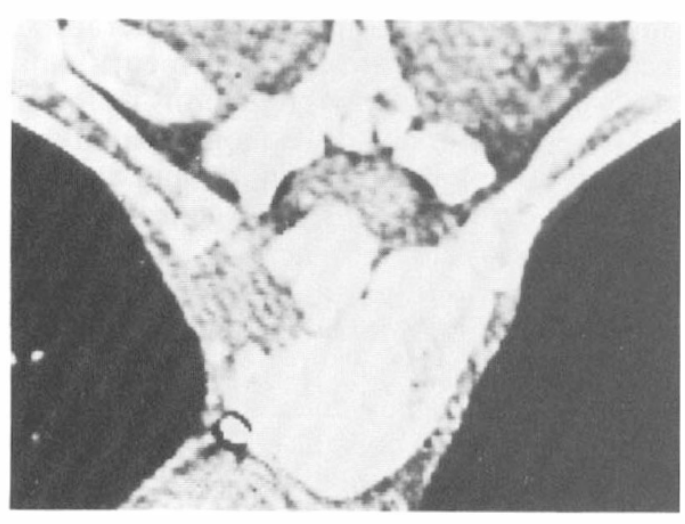

Figure 5 15.2.90: Postoperative $\mathrm{CT}$ at 5 months. Axial scan shows further assimilation of the mass into the surgical bed and better delineation of the less obstructed spinal cord now more clearly outlined by extradural fat.

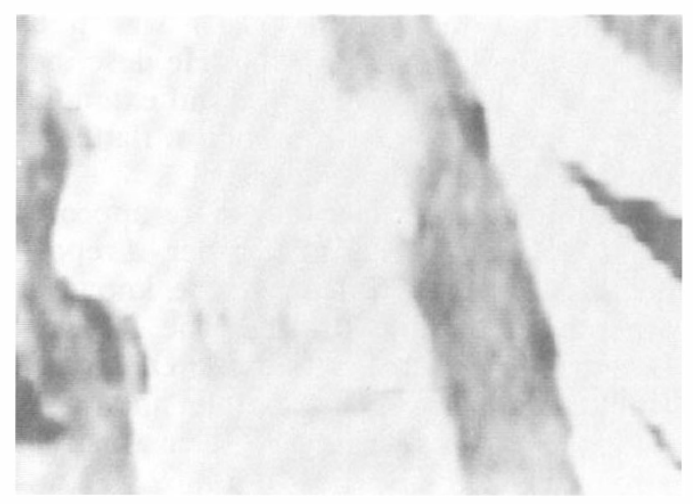

Figure 6 15.2.90: Postoperative $\mathrm{CT}$ at 5 months. Comparable sagittal image shows further consolidation of the vertebral interbody grafts at the operation site.

group in 1974. The authoritative paper of Tsuyama $^{3}$ is based on that investigation committee report on OPLL on 2100 patients. Tsuyama credits $\mathrm{Key}^{4}$ with providing the earliest account of compression of the spinal cord by OPLL.

In their paper on OPLL Wennekes et al ${ }^{5}$ also credit Key with the first description of this disease in a Japanese patient. They state that only 20 cases of this disease in non Japanese patients had been reported in the Anglo-Saxon literature.

On referring to Key's paper 'On paraplegia depending on disease of the ligaments of the spine', interesting accounts of the clinical management of 6 cases of paraplegia are given but these were clearly due to infective lesions of the spine and in only 2 had limited postmortem examinations been made, the pathology reports bearing no resemblance to the now familiar findings in OPLL. None of these patients were Japanese. Key concluded: 'I am inclined, by long observations of spinal affections, to think that the ligaments are more frequently in fault than any of the structures of the spinal column; and that many of the cases of paralysis,.... will be found by dissection, to depend on an altered condition of those textures'.

The recent paper by Terayama $^{6}$ deals with genetic studies in 347 Japanese families with OPLL and concludes that the disorder is possibly controlled by autosomal dominant inheritance.

The incidence of OPLL in Caucasians is unknown $^{7}$ though reports vary between claims that it is not rare $^{8}$ and that it is an extremely rare disease. ${ }^{9}$ The association of OPLL with other lesions such as diffuse idiopathic skeletal hyperostosis, ossification of the ligamentum flavum, ankylosing spondylitis and primary hyperparathyroidism has been stressed by various authors. ${ }^{10-12}$ The distribution of OPLL has been discussed in a number of papers. ${ }^{13-16}$

OPLL in the thoracic spine is usually asymptomatic. As a cause of paraplegia it is certainly rare. Forcier and Horsey ${ }^{17}$ reported one case with evidence of spinal cord compression at the thoracolumbar junction which showed some improvement following decompressive laminectomy.

We have found only 2 reports of OPLL in the British medical literature. Hanna ${ }^{18}$ described the case of a 58 year old male Caucasian with OPLL from C2-C4. Operation was refused by the patient. Lecky and Britton, ${ }^{19}$ from Guy's Hospital, described the case of a 42 year old West Indian immigrant to Britain who presented with neurological symptoms due to this lesion at the $C 4 / 5$ level. No operation was offered.

The purpose of presenting our case is to draw attention to this condition occurring high in the thoracic region in an English patient. We have provided a detailed description of the operation to highlight the 
potential hazards of surgery and how to avoid them. Onji et al $^{20}$ described a number of the serious problems which may be encountered during surgery for this condition, including irreversible damage to the spinal cord, CSF fistula and meningitis. We stress the importance of avoiding efforts to remove the bony plaque from the dura if it is firmly attached, as dural tears may be impossible to repair in the thoracic region.

\section{References}

1 Tsukimoto H (1960) A case report-autopsy of syndrome of compression of spinal cord owing to ossification with spinal canal of cervical spine. Arch Jap Clin 29: 1003-1007.

2 Breidahl P (1969) Ossification of the posterior longitudinal ligament in the cervical spine. Aust Radiol 13: 311-313.

3 Tsuyama N (1984) Ossification of the posterior longitudinal ligament of the spine. Clin Orthop 184: 71-84.

4 Key AC (1938) On paraplegia depending on disease of the ligaments of the spine. Guys Hospital Medical Report: 17-34.

5 Wennekes MJ, Anten HWM, Korten JJ (1985) Ossification of the posterior longitudinal ligament. Clin Neurol Neurosurg 87(4): 297-302.

6 Terayama K (1989) Genetic studies on ossification of the posterior longitudinal ligament of the spine. Spine 14: $1184-1191$.

7 Firooznia H, Benjamin VM, Pinto RS et al (1982) Calcification and ossification of posterior longitudinal ligament of the spine. N Y State J Med: 1193-1197.

8 McAfee PC, Regan JJ, Bohlman HH (1987) Cervical cord compression from ossification of the posterior longitudinal ligament in non-orientals. J Bone Joint Surg 4: 569-573.

9 Klara PM, McDonnell DE (1986) Ossification of the posterior longitudinal ligament in Caucasians: diagnosis and surgical intervention. Neurosurg 19 (2): 212-217.

10 Resnick D, Guerra J Jr., Robinson CA, Vint VC (1978) Association of diffuse idiopathic skeletal hyperostosis (DISH) and calcification and ossification of the posterior longitudinal ligament. Am J Roentgenol 131: 1049-1053.

11 Dietemann JL, Dirheimer Y, Babin E, Edel L, Dosch JC, Hirsch E, Wackenheim A (1985) Ossification of the posterior longitudinal ligament. J Neuroradiol (Paris) 12: 212-222.

12 Yoshizawa H, Ohiwa T, Iwata H, Nishizawa K, Nakamura H (1988) High thoracic myelopathy due to ossification of the ligamentum flavum. Neuro Orthop 5: 36-44.

13 Ono M, Russel WJ, Kudo S et al (1982) Ossification of the thoracic posterior longitudinal ligament in a fixed population. Neuroradiol 143 (2): 469-474.

14 Miyasaka K, Kaneda T, Ito T, Takei H, Sugimoto S, Tsuru M (1982) Ossification of spinal ligaments causing thoracic radiculomyelopathy. Neuroradiol 143(2): 463-468.

15 Yonenobu K, Ebara S, Fuiiwara K et al (1987) Thoracic myelopathy secondary to ossification of the spinal ligament. J Neurosurg 66: 511-518.

16 Epstein NE, Epstein JA (1989) Simultaneous ossification of the posterior longitudinal ligament in the cervical and lumbar spinal canal. Neurol Orthop 8(1): 45-53.

17 Forcier P, Horsey WJ (1970) Calcification of posterior longitudinal ligament at thoraco-lumbar junction. Case report. J Neurosurg 32: 682-685.

18 Hanna M, Watt I (1979) Posterior longitudinal ligament calcification of the cervical spine. Br J Radiol 52: 901-905.

19 Lecky BFR, Britton JA (1984) Cervical myelopathy due to ossification of the posterior longitudinal ligament. J Neurol Neurosurg Psychiatry 47: 1355-1361.

20 Onji Y, Akiyama HN, Shimomura Y, Ono K, Hukuda S, Mizuno S (1967) Posterior paravertebral ossification causing cervical myelopathy. J Bone Joint Surg 49A: 1314-1328. 